\title{
A survey of the aeromycota of urban Sydney and its correspondence with environmental conditions: grass as a component of urban forestry could be a major determinant
}

\section{Peter J. Irga}

\section{Fraser R. Torpy}

Plants and Environmental Quality Research Group, School of the Environment, Faculty of Science, University of Technology Sydney, P.O. Box 123, Broadway, NSW 2007, Australia

e-mail: Fraser.Torpy@uts.edu.au

Phone: +6129514 4150

Fax +61295144079

\begin{abstract}
A comprehensive survey of airborne fungal spores has been lacking for the Sydney region. This study determined the diversity and abundance of outdoor airborne fungal concentrations in urban Sydney. Monthly air samples were taken from 11 sites in central Sydney, and culturable fungi identified and quantified. The genus Cladosporium was the most frequently isolated spore type, with a frequency of $78 \%$ and a mean density of 335 $\mathrm{CFU} / \mathrm{m}^{3}$. The next most frequently encountered genus was Alternaria, occurring in $53 \%$ of samples with a mean of $124 \mathrm{CFU} / \mathrm{m}^{3}$. Other frequently identified fungi, in decreasing occurrence, were: Penicillium, Fusarium, Epicoccum, Phoma, Acremonium and Aureobasidium. Additionally, seasonal and spatial trends of airborne fungi were assessed, with increases in total fungal concentrations experienced in the summer months. The correspondence between a range of key environmental variables and the phenology of airborne fungal propagules was also examined, with temperature, wind speed and proximal greenspace having the largest influence on the aeromycota. If the greenspace comprised of grass, stronger associations with fungal behaviour were observed.
\end{abstract}

Keywords: Airborne fungi; urban; aeromycota; bioaerosols; Sydney; seasonal; grass 


\section{Introduction}

Airborne fungal spores are ubiquitous, and constitute a large proportion of the biological matter that is present in the air (Bauer et al. 2008). Exposure to this fungal material can elicit an array of health complications; ranging from exacerbating asthma (Tham et al. 2014), to allergic alveolitis (Bush 2009), and even systemic disease (Crook \& Burton 2010).

In Australia, Cladosporium and Alternaria are the two most common airborne fungal genera, and the volume of material inhaled from either genus can be very high, even during non-conducive outdoor conditions, with individuals inhaling up to 794 Cladosporium spores/h and 396 Alternaria spores/h in urban environments (Mitakakis et al. 2000). Such exposure can induce allergic rhinitis symptoms in sensitized individuals (Andersson et al. 2003).

As these organisms pose a potential human health risk, documentation of variations in the numbers and taxonomic composition of the mycobiota is of importance to public health (Denning et al. 2006). The propagule density and species composition of airborne fungi are known to vary substantially among studies made in different parts of the world (Fröhlich-Nowoisky et al. 2012, Kemp et al. 2003, Oliveira et al. 2009), thus making local surveys imperative. It is thought that variations amongst geographical locations occur because of local environmental conditions, varying growth substrates, and human activities (Gots et al. 2003). These contributing variables can differ greatly from region to region when considering human population, usage and climatic influences and from urban to rural areas (Simeray et al. 1993). Thus, each survey is exclusive to the area from which samples were collected and any associated site specific environmental and temporal conditions.

In Australia, the diversity of airborne fungi has been relatively well documented for most cities with studies in: Brisbane (Hargreaves et al. 2003, Rutherford et al. 1997), Melbourne (CSIRO 2010, Derrick and McLennan 1963, Dharmage et al. 1999, Mitakakis et al. 1997, Mitakakis \& Guest 2001), Adelaide (Gaskin et al. 2012) and Perth (Kemp et al. 2003), as well as rural studies in Northern NSW (Green et al. 2006), Moree and Wagga Wagga (Mitakakis and McGee 2000, Mitakakis et al. 2001) and the La Trobe valley (Garrett et al. 1997).

A comprehensive survey of fungal spores is lacking for the Sydney region (Burton \& Katelaris 2014), although a number of studies have been undertaken on specific spore types exclusively. Stennett and Beggs (2004) documented peak atmospheric Alternaria concentrations in late summer periods for Sydney, with positive associations between Alternaria spores and temperature as well as air pressure. Bass and Morgan (1997) similarly noted that Alternaria spores in Western Sydney were mainly prevalent in late spring and summer.

Only three studies on the diversity of airborne fungi have been conducted in Sydney. The first; Frey and Durie (1960), addressed the species composition of airborne moulds in Sydney by sampling agar plates left about in open areas. However, it has since been established that more buoyant fungal spores, including potential pathogens such as Aspergillus and Penicillium spp. (Bunse \& Merk 1992), do not penetrate the agar's boundary layer (Dix and Webster 1995), and thus will be underestimated by this method. Accordingly these genera, and an unknown number of others, may have been severely underestimated by Frey and Durie (1960). Burton and Katelaris (2014), surveyed airborne fungal spores with a focus on Didymella spp. and Coprinus spp., however their investigation was limited to an area 54 kilometres from the city's centre. In a third Sydney study, Torpy et al. (2013) assessed the relationship between indoor plants and indoor aeromycota. Seasonal indoor air samples from the offices of two buildings in Sydney were compared to offices in the same buildings with plants present. Outdoor air samples were taken in order to act as reference samples only, thus this study's conclusions is limited to the locations of the buildings rather than establishing a general survey of the density and community structure of the aeromycota in Sydney.

The research presented here aimed to provide a comprehensive survey of the ecology and phenology of the aeromycota of inner Sydney. The objectives of this study, therefore, were to:

- Determine the diversity and abundance of outdoor airborne fungal concentrations for urban Sydney

- Examine seasonal trends of airborne fungi in urban Sydney 
- Investigate the spatial variability of the aeromycota across urban Sydney

- Determine the correspondence between a range of key environmental variables and the diversity and abundance of airborne fungi 


\section{Methods and Materials}

\subsection{Study area}

Sydney, Australia is a city with a population of 4.5 million and lies on a coastal lowland plain between the Pacific Ocean and elevated sandstone tablelands. The climate for Sydney is warm and temperate. Days in which rainfall events occur are evenly distributed throughout the year for Sydney, however rainfall volume is at its most in Autumn.

\subsection{Sample sites}

All samples were taken between September 2013 and August 2014. Monthly samples were collected across eleven sites within the City of Sydney Local Government Area (LGA). Sites were selected to provide a range of different conditions with respect to population and traffic density and usage, and greenspace / urban forest density (Figure 1), and are detailed below:

- Newtown $(-33.9108,151.2074)$, is a medium density residential and parkland area. The quantity of greenspace of Newtown is relatively high, with $>20 \%$ greenspace cover. The greenspace at this site was comprised mainly of grassed lawns and a combination of the following tree species: Casuarina spp., Corymbia maculate, Angophora costata and various eucalypt species eg. Eucalyptus sideroxylon.

- Centennial Park (-33.9010, 151.2234), is a medium density residential and parkland area. The quantity of greenspace of Centennial Park is relatively high and is comprised of grassed lawns, pond side vegetation and a combination of the following trees: Ficus macrophylla, Araucaria cunninghamii, various eucalypts eg. Eucalyptus saligna and Melaleuca quinquenervia and Liquidambar styraciflua.

- Rushcutters Bay $(-33.8739,151.2286)$, is a medium density residential harbour side area. The quantity of greenspace in Rushcutters Bay is high due to highly planted residential areas and is mainly comprised of Lophostemon confertus, Ficus macrophylla, Jacaranda spp., Eucalyptus sideroxylon, Eucalyptus saligna.

- Prince Alfred Park (-33.8884, 151.2035), is a medium density residential and parkland area. The quantity of greenspace in Prince Alfred Park is moderately high and is comprised of Lophostemon confertus, Melaleuca quinquenervia, and Australian figs (Ficus spp.)

- Surry Hills $(-33.886,151.2138)$, is a medium density residential and commercial area. The quantity of greenspace in Surry Hills is moderately high due to highly planted residential areas and is mainly comprised of Lophostemon confertus, Liquidambar styraciflua, Platanus x acerifolia, and Poplus nigra.

- Chippendale $(-33.8877,151.1962)$, is a medium density residential and commercial area. The quantity of greenspace in Chippendale is moderate, and comprised of the street trees: Lophostemon confertus, Liquidambar styraciflua, Platanus x acerifolia.

- Glebe $(-33.8823,151.185)$, is a medium density residential area, with moderate greenspace. The street trees present are Callistamon spp., Lophostemon confertus, Platanus x acerifolia, Jacaranda spp.

- Haymarket $(-33.8801,151.2026)$, is a high density residential and commercial area, with relatively low greenspace density. Only street trees are present dominated by the species Platanus x acerifolia.

- Zetland (-33.9108, 151.2074), is a mixed industrial and high density residential and commercial area. The greenspace in Zetland is low, and is dominated by the species Lophostemon confertus.

- Town Hall $(-33.873,151.2051)$, is a high density commercial area, with very low greenspace. Street trees only, comprised of Platanus $\mathrm{x}$ acerifolia and Poplus nigra.

- $\quad$ Pitt St (-33.8738, 151.2081), is a high density commercial area, with very low greenspace. Street trees only were present, and were only of the species Platanus x acerifolia and Poplus nigra.

Monthly samples were taken on a single day, mid-week, between 1000 and 1400 in an effort to eliminate diurnal variations. A temporarily independent design was implemented, where a single air sample was collected from different randomly selected points within the $100 \mathrm{~m}$ radius of the site centres each month, to negate the 
requirement for repeated measures analysis. No samples were taken whilst it was raining, and a minimum wait of two days was given after any rain event before the collection of samples. These procedures were necessary as rainfall has been shown to 'wash' spores and other particle matter out of the atmosphere (Nishihara et al. 1989).

\subsection{Environmental conditions}

It was predicted a priori that plant material may have an influence on aeromycota behaviour. Greenspace at the sites was approximated across a $500 \mathrm{~m}$ radius circle from the geographical centre of each sample site (Table 2). These areas were further subdivided into $250 \mathrm{~m}$ and $100 \mathrm{~m}$ radius areas, forming areas of 3.14, 16.5 and 59.0 ha respectively. The proportion of these areas under tree cover, grass cover and also total greenspace was calculated using Daft Logic Google Maps Distance Calculator (2013) from the satellite images available in Google maps. The zoom capability of the Google maps allowed accurate estimates of green space cover to be made. As it has been demonstrated that cropping activities (Mitakakis et al 2001) and the mowing of lawn grasses can aerosolize fungal spores (Comtois et al. 1995), no sampling was undertaken when this occurred, to the author's knowledge.

All site samples were collected for a length of 5 minutes per site, apart from the fungal air samples which are described below, from approximately a height of $170 \mathrm{~cm}$ to replicate as closely as possible the breathing space of an average human. Temperature and relative humidity were recorded as part of the field sampling procedures, using a Multifunction Environment meter (Digitech, China). A Turbometer Davis anemometer (Davis Instruments Corp. Hayward, California USA) was used to measure wind speed and direction specific to the locations sampled.

Specific meteorological data such as relative humidity (daily average), rainfall (previous week, month and days since last rain event), temperature (daily and weekly maxima and minima) and prevailing wind direction (strength, direction over $24 \mathrm{~h}, 48 \mathrm{~h}$ and weekly time scales) were obtained from the Australian Bureau of Meteorology (2014).

\subsection{Fungal air samples}

Airborne mould spore samples were collected using a Reuter Centrifugal air sampler, which operates on the principle of impacting particles from the sample air onto an agar medium coating a plastic backing strip by centrifugal force (Laflamme and Miller 1992). Each air sample was 80 litres in volume (2 minute duration). Sabouraud's dextrose agar (SDX; Biotest AG, Germany) was used as the fungal growth medium, as its low $\mathrm{pH}$ inhibit most bacterial growth. On return to the laboratory, the medium was incubated for 7 days at $23^{\circ} \mathrm{C}$. Mould colonies were identified to genus level using gross microscopic morphology, utilising the descriptions and keys of Alexopoulos et al. (1996), Ellis et al. (2007), Klich \& Pitt (1988) and Larone (2002). If colonies were then unidentifiable, they were subcultured onto new Sabouraud's Dextrose Agar and re-incubated until sporulation, or deemed sterile mycelia after a minimum period of 21 days. Special attention was paid to Aspergillus spp., as species within this genera can cause a range of saprophytic, invasive and allergic diseases, some with high mortality (O'Gorman 2011). Thus, colonies of Aspergillus were further identified to species level.

\subsection{Data analysis}

Univariate analysis of the data was conducted utilising SPSS Version 21.0 (SPSS Inc., USA) and multivariate analysis using PRIMER v6.1.6 (Primer- E Ltd, 2006).

Differences in fungal spore concentrations across sites and months were examined by general linear model analyses of variance (ANOVA) and P-values less than 0.05 were considered significant. Fungal community differences across months were compared using analyses of similarities (ANOSIM) using a Euclidean distance similarity matrix. Similarity percentages analysis (SIMPER) was also used, to identify the genera that were responsible for differences across groups (sites and months). Linear associations between fungal density and diversity with individual environmental conditions were examined by computing Pearson correlation 
coefficients. Stepwise multiple linear regression was carried out to determine the relative influence of the environmental variables on the variance in fungal levels. 


\section{Results}

Table 3 shows the frequency at which the various genera were detected in the 132 air samples taken during the study, along with their average propagule density (as colony forming units: CFU). The genus Cladosporium was the most frequently isolated spore type, with a frequency of $78 \%$ and a mean density of $335 \mathrm{CFU} / \mathrm{m}^{3}$. The next most frequently encountered genus was Alternaria, occurring in $53 \%$ of samples with a mean of $124 \mathrm{CFU} / \mathrm{m}^{3}$. Other frequently-identified fungi, in decreasing occurrence, were: Penicillium, Fusarium, Epicoccum, Phoma, Acremonium and Aureobasidium. All other genera were encountered in less than $20 \%$ of samples.

\subsection{Seasonal patterns of airborne fungi}

Total airborne propagule densities showed temporal patterns across the study period (Figure 3), with higher concentrations during the spring and summer, and lower numbers during winter. The mean total number of CFU throughout the year ranged from $425 \mathrm{CFU} / \mathrm{m}^{3}$ in August (mid-winter) to $1531 \mathrm{CFU} / \mathrm{m}^{3}$ in February (late summer; Figure 2). This seasonal periodicity was expected, as the factors that we proposed a priori that might influence the proliferation of moulds (humidity, warm temperature and rainfall) also fluctuate throughout the year, and it was predicted that various fungi would have preferences for specific environmental conditions. Thus the relationship between total airborne propagule density and a range of climatic and weather variables was tested statistically (see below).

The number of genera of fungi encountered was less variable through time, with mean generic diversity ranging from 4 to 15 genera per sample over the study period, and no detectable temporal trend was present.

As stated previously, Cladosporium was the most frequent genus encountered; and was detected in high concentrations across all sampling months relative to the other fungi encountered, albeit with clear seasonal variability (Figure 4). Alternaria and sterile mycelia were somewhat less frequently identified, but tended to show seasonal trends whereby they occurred more frequently and comprised a larger percentage of total spores during the summer months.

When comparing airborne fungal communities across months; ANOSIM indicated that the only significant pattern in the dataset was that the community structures of fungi identified in the summer months (December, January and February) were significantly different from all other months (Global $\mathrm{R}=0.175, \mathrm{P}=0.01$ ). In all cases, SIMPER analysis identified increased concentrations of Cladosporium as the primary change differentiating the summer samples from the other months, contributing to $23.8-45.7 \%$ of the between-month variance. The only other taxa that contributed more than $10 \%$ of the seasonal differences were increased Alternaria and Epicoccum, contributing $11.60 \%$ and $10.52 \%$ of the between seasonal variance respectively.

\subsection{Spatial patterns of airborne fungi}

The mean total number of fungal colony forming units identified at the sites ranged from $346 \mathrm{CFU} / \mathrm{m}^{3}$ in the highly urban Haymarket to $2250 \mathrm{CFU} / \mathrm{m}^{3}$ in the Newtown site, which was located in Sydney Park, a large, predominantly grassed parkland (Figure 4).

Amongst sites, the Newtown samples had significantly higher mean numbers of fungal genera, followed by another parkland site; Centennial park (GLM ANOVA both $\mathrm{P}<0.05$, compared to all other sites).

The other sites, which all had far lower levels of greenspace than the Newtown and Centennial Park sites, all supported statistically similar fungal densities (GLM ANOVA; P > 0.05), apart from the Haymarket sample site, which had significantly lower concentrations on average than all the other sites (GLM ANOVA; P $<0.05$, Fig 4).

Locations with high fungal densities also supported higher diversity of fungal species (Pearson's $\mathrm{r}=0.302$, $\mathrm{P}<0.000)$. 
Whilst several genera showed considerable variation throughout the year, few genera demonstrated trends between the different sites, with some quantitatively minor exceptions: significantly more Epicoccum was found in Newtown (GLM ANOVA; P < 0.05), and yeasts were frequently found in higher numbers in Centennial park (GLM ANOVA; P < 0.05). At a community level, ANOSIM did not detect differences in community structure across sites (Global $\mathrm{R}=0.008, \mathrm{P}=0.329)$.

\subsection{Identification of pathogens}

Few pathogenic fungi were identified in the samples, and the densities of the all allergenic groups of most concern, including genera from the pleospora like Alternaria, were within an acceptable range for human health.

A small number of potentially opportunistic organisms of human health concern were encountered: for example several Aspergillus spp. were documented; however no dimorphic or systemic pathogens were present, nor were any dermatophytes. Yeast isolates were tested with a capsule stain to determine whether there was a possibility of Cryptococcus spp, however none were found.

Seven species of Aspergillus were identified throughout the entire study, with Aspergillus versicolour being the most prevalent, occurring in $6.8 \%$ of samples (Table 4). Aspergillus fumigatus, the species of most concern (O’Gorman 2011), was detected much less frequently, occurring in $1.5 \%$ of samples.

\subsection{Environmental predictors of aerosolized fungi}

Whilst many correlations between environmental conditions and aeromycota were significant, values of the correlation coefficients obtained were low in all cases (none exceeds 0.6).

Total airborne fungal CFU were significantly correlated with wind speed measured at the time of sampling $(\mathrm{r}=0.563, \mathrm{P}=0.000)$ and temperature $(\mathrm{r}=0.233, \mathrm{P}=0.007)$. Total spores were also correlated with percentage greenspace at all levels of measurement (100, 250 and $500 \mathrm{~m}$ radii); where increasing greenspace was positively and significantly correlated to increases in total fungal density ( $\mathrm{r} \geq 0.351, \mathrm{P}<0.001$ in all cases).

Number of genera was significantly correlated with wind speed measured at the time of sampling $(\mathrm{r}=0.451$, $\mathrm{P}=0.000)$, total rain in the past month $(\mathrm{r}=0.187, \mathrm{P}=0.032)$, total rain in the last week $(\mathrm{r}=0.179, \mathrm{P}=0.049)$ and negatively correlated with temperature $(\mathrm{r}=-0.211, \mathrm{P}=0.015)$ and time since last rain event $(\mathrm{r}=-0.228, \mathrm{P}=0.009)$. As per total spore concentration, number of genera was also correlated with percentage greenspace at all levels of measurement (100, 250 and 500 m radii; $r \geq 0.273, \mathrm{P}<0.001$ in all cases).

To test the effects of different greenspace components, percentage greenspace was split between canopy coverage (ie. trees and shrubs) and grass coverage. When analysed, only grass cover was found to be significantly correlated with increases in total fungi and number of genera at all levels of measurement (100, 250 and $500 \mathrm{~m}$ radii; $\mathrm{r} \geq 0.424, \mathrm{P}<0.001$ in all cases), whilst no relationships were found between increasing tree canopy coverage and increasing total fungi / generic diversity at all three levels of measurement ( $p>0.05$ in all cases).

Multiple stepwise linear regression analysis was used to determine which environmental variables were the strongest predictors of the fungal bioparticle air quality variables as per Green et al. (2003). The analysis ranked the variables in order of predictive power for total propagule concentration, with backward elimination performed to check the significance of each variable.

The analysis indicated that only three predictors were worthy of consideration, as these variables were the only ones that were statistically significant and adding further predictors to the model made little contribution $(<2 \%)$ to its overall explanatory power.

For total concentration of airborne fungi, the grass cover within a $100 \mathrm{~m}$ radius was the largest contributor to the overall variation in the model, explaining $35.55 \%$ of the linear pattern in the fungal data $\left(\mathrm{R}^{2}=35.55\right)$. Adding wind speed to the model explained an additional $14.72 \%$ of the variation, and adding total rain in the past month 
added $4.65 \%$ explanatory power. The three variable model thus explained $54.87 \%$ of the variability in the data set (Table 5), and is expressed in equation 1 :

\section{Equation 1}

Total airborne fungi $\left(\mathrm{cfu} / \mathrm{m}^{3}\right)=16.6 \mathrm{a}+138 \mathrm{~b}-1.9 \mathrm{c}+370.1$

Where $\mathrm{a}=$ Percentage grass cover within $100 \mathrm{~m}$ radius, $\mathrm{b}=$ Wind speed, $\mathrm{c}=$ Total rainfall in the past month

Similarly, when the number of genera encountered was used as the response variable, again only three predictors explained the majority of the variation within the model: with wind speed explaining $28.33 \%$ of the linear pattern in the fungal data $\left(\mathrm{R}^{2}=28.33\right)$. Adding mean maximum temperature for the month to the model explained an additional $4.42 \%$ of the variation, and adding total rain in the past month added $4.26 \%$ explanatory power. The three variable model thus explained $37.01 \%$ of the variability in the data set (Table 5), and is expressed in equation 2 :

\section{Equation 2}

Number of taxa encountered (per $80 \mathrm{~L}$ sample) $=0.218 \mathrm{a}-0.218 \mathrm{~b}+0.0065 \mathrm{c}+9.8$

Where $\mathrm{a}=$ wind speed, $\mathrm{b}=$ temperature, $\mathrm{c}=$ Total rainfall in the past month. 


\section{Discussion}

The current study provides the most comprehensive assessment to date on the data on the density and prevalence of culturable airborne fungi in the outdoor air of urban Sydney.

Cladosporium, Alternaria and Penicillium were common across spatial and temporal samples. The genera encountered in this study not only resemble the composition of fungi found in other major city centres in Australia (Garrett et al. 1997; Mitakakis \& Guest 2001; Rutherford et al. 1997) but also other regions that have comparable climates: Santa Fe City, Argentina (Basilico et al. 2007), Porto, Portugal (Sousa et al. 2008) and Granada, Spain (Sabariego et al. 2000). Similarly, previous work has identified increases in spore density and diversity during summer months. This could be due to changes in meteorological factors occurring in summer, as we detected positive associations between variables that increase during summer, such as temperature and rainfall, and many fungal genera. Most fungi had positive associations with wind speed, which is logical as wind is known to be a major vector of spore dispersal (Lin \& Li 2000).

Much like the aeromycology of Brisbane, a more northerly Australian city that has been previously studied, Cladosporium was the dominant airborne spore type, whilst Alternaria became consistently more numerous during summer (Rutherford et al. 1997). However, the total spore counts in Brisbane reached a maximum in late summer and early autumn, whereas we detected peak density in Sydney to occur several weeks earlier. Another study conducted in Brisbane (Hargreaves et al. 2003), noted that the most frequently isolated fungal genera were Cladosporium, Curvularia, Alternaria, Fusarium and Penicillium; fungal genera that were also the most common in this study. Correspondingly, in a Melbourne study utilising a Burkard air sampler, (Mitakakis \& Guest 2001) Cladosporium was the most prevalent spore type, followed by numerous basidiospores and sexual ascospores. The latter spore types, if encountered in the current study, may have been deemed sterile mycelia, as they may not have grown on the media we used. Alternatively, the Burkhart method does not permit easy discrimination of many genera that produce small conidia (Mitakakis \& Guest 2001), such as Penicillium and Aspergillus, thus making detailed comparison of bioparticle and culturable fungi studies difficult.

Further, the current findings are very similar to the only other study to address fungal genera composition in urban Sydney: Torpy et al. (2012); except we found the concentration of total spores to be much higher in spring than Torpy et al. (2012) recorded. These variations in numbers and diversity of spores encountered in this study could potentially be attributed to spatial differences in microclimate and vegetation, as Torpy et al. (2012) only studied a single site that would only be comparable to the Haymarket site in the current work.

Interestingly, there were no differences in overall community assemblage (ie. the relative frequency of the different genera) across sites, however some individual genera did show trends; Epicoccum was frequently found in Newtown. As Epicoccum is a known plant endophyte and involved in the early stages of plant decomposition (Thormann et al. 2003), there may be a potential urban forestry/ aeromycology spore load association, for this particular site. Yeasts were frequently found in higher numbers in Centennial Park. Yeasts are ubiquitous and abundant in the air and are often phylloplane organisms (Fonseca \& Inácio 2006), thus being encountered in an area with relatively high density of greenspace comes as no surprise, however the high frequency at Centennial park compared to other planted areas requires further investigation.

Amongst sites, the Newtown samples had significantly higher mean numbers of fungal species, followed by another parkland site; Centennial park, indicating that greenspace, especially the grass component, could be a major determinant of the density of airborne fungi in urban areas. As hypothesised by Mitakakis et al. (2001) and Hargreaves et al. (2003), elevated mould spores in urban areas could be a result of proximal vegetation. In the current study, total spores, number of genera, and the densities of Cladosporium, Alternaria and Epicoccum all showed positive correlations with greenspace. One of the more noteworthy findings of this work is the finding that grass coverage consistently showed stronger associations to the spore density/diversity more so than tree and shrub canopy coverage. It was previously unknown whether urban forestry type would have a quantifiable influence on fungal phenology. One potential reason as to why grass contributed to more fungi is the way in which the streets are maintained: trees tend to line fully paved surfaces in Sydney and these street surfaces are cleaned regularly, as opposed to grass cover, which exists in parks, and may harbour greater 
quantities of decaying organic material; which, if the fungi are saprophytes, could proliferate and then produce aerosolized spores. It is plausible that saprobic colonization and sporulation of non-systemic grass endophytic fungi could become unrestrained when their host plant tissue dies (Vázquez de Aldana et al. 2013).

Additionally, turf grass in urban areas is regularly mown: potentially mechanically aerosolizing endophytic and epiphytic fungi (Streifel 1988) and exposing damaged plant tissues and leaking protoplasm which may encourage fungal growth. Comtois et al (1995) demonstrated that the act of mowing lawns can aerosolize fungal spores, increasing the exposure of lawn mowing workers to aeroallergens. Similarly, previous work by Mitakakis et al (2001) showed crops and the harvest of crops increase aeromycota concentrations in proximal towns (Mitakakis et al. 2001). No urban vegetation was disturbed or molested at the time of sampling; to this author's knowledge.

Fungal propagule concentrations in the air and their taxonomic compositions are known to fluctuate, a consequence of the interaction between biological and environmental factors including geographical location, human activity and local source of vegetation (Lacey 1981). Further, the effects of meteorological factors on the fungal occurrence in the air have been highlighted by many authors for many different regions (eg. GrinnGofron and Bosiacka 2014). Total airborne fungal CFUs and number of genera encountered were significantly correlated with a number of environmental conditions, including wind speed and temperature. This corresponds with the findings of many previous studies that have assessed relationships with airborne fungal propagules and environmental variables (Li and Kendrick 1995, Grinn-Gofroń and Bosiacka 2015, Rutherford 1997, Stannett and Beggs 2004, Oliviera et al 2009, Goncalves 2010). When environmental variables were analysed for their combined effects on total airborne fungal CFUs, percentage grass cover within $100 \mathrm{~m}$ radius, wind speed and total rainfall in the past month explained $54.87 \%$ of the variation. Remarkably, percentage grass cover within $100 \mathrm{~m}$ radius as a variable was more important in the multiple stepwise linear regression model than any meteorological variable measured. Considerable research has found associations with wind and precipitation with airborne fungal propagules (Li and Kendrick 1995, Mitakakis et al. 2001, Trimmer et al. 1998), however rarely has any study incorporated a potential source like urban vegetation in to their analysis.

Accordingly, the diversity of culturable airborne fungi was associated with wind speed as well as several precipitation variables, however higher temperatures were associated with decreased diversity of genera encountered. This could be due to the fact that higher temperatures facilitate fungal sporulation thus increasing diversity, while precipitation potentially removes some spore types from the atmosphere, reducing diversity. Nonetheless, some studies do find positive associations with some spore types and precipitation (Kurkela 1997), potentially a result of increase humidity inducing sporulation (Quintero et al. 2010) or rain drops facilitating the dispersion of these spores from vegetation (Levetin and Horner 2002).

Surprisingly, no associations were found with humidity, possibly because Sydney's humidity levels do not fluctuate throughout the year as much as other geographical regions across season. Cladosporium and Alternaria, the most dominant taxa identified in this study, have been found to be most prevalent during midday when the humidity is less and the wind is dry (Burch and Levetin 2002), as they require relatively lower humidity to sporulate.

It is evident that associations between airborne fungal propagule density and different meteorological parameters are complex (Oliviera 2009), as most mathematical models that attempt to predict airborne usually forming weak relationships. Clearly, there are many variables that determine the density and diversity of fungal spores in the atmosphere, and not one variable is a main determinant.

Few human pathogens were identified in the survey: Aspergillus spp. was present in $15.2 \%$ of samples however accounted for less than $0.8 \%$ of the total fungal propagules detected, which is comparable to the ambient background frequencies recorded by (Recer et al. 2001). Aspergillus fumigatus was found in less than $1.5 \%$ of samples taken, with a mean concentration of $0.8 \mathrm{CFU} / \mathrm{m}^{3}$. There are no universally recommended threshold limits on airborne A. fumigatus, however the Spanish Society of Infectious Diseases and Clinical Microbiology recommends concentration maxima for hospitals at $0.5 \mathrm{CFU} / \mathrm{m}^{3}$ for operating rooms and $25 \mathrm{CFU} / \mathrm{m}^{3}$ for other parts of the hospital (Ruiz-Camps et al. 2011). The concentrations of aspergilli detected in the current work were thus of an acceptable level for human health. 
Associations have been made with increases in fungal exposure and allergenic symptoms, incidence of asthma and unscheduled hospital visitations (Pongracic et al. 2010). In this study, the highest concentrations of airborne fungi were observed in summer. Asthma hospitalisations tend to increase in summer periods (AIHW 2013), a pattern that is potentially related to increases in allergens at this time of year (Sharpe et al. 2015). This trend is less distinct in northern Australia, where the seasonal differences are less defined (Sharpe et al. 2015). No Australian study is yet to find a relationship between allergic symptoms or hospital admissions and airborne fungal concentrations in any Australian city (Hanigan \& Johnston 2007, Tham et al. 2014), however positive associations have been demonstrated in studies from the USA (Pongracic et al. 2010), United Kingdom (Atkinson et al. 2006) and Canada (Dales et al. 2004).

Further work that utilises molecular methods for the characterization of fungal diversity such as the DNA sequencing of sampled fungi could be utilised to better identify the sterile mycelia encountered in culturable fungal studies (Kauserud et al. 2005, Lang-Yona et al. 2012). Similarly, work that considers the concentrations of specific urban plant species in urban areas and their potential associations to the proximal aeromycota needs to be explored.

\section{Conclusions}

The work here presents a comprehensive survey of the culturable aeromycota of Sydney by determining the diversity and abundance of outdoor spore concentrations for urban Sydney. Seasonal trends of airborne fungi in urban Sydney were observed, with increases in spore concentrations experienced in summer months. The environmental variables that made the largest detectable influence to the diversity and abundance of fungal spore loads were temperature, wind speed and proximal greenspace. If the greenspace comprised of grass, stronger associations to aeromycology were observed.

\section{Acknowledgements}

Peter Irga conducted majority of this work with the support of an Australian Postgraduate Award, funded by the Australian Government and a grant from the City of Sydney's Environmental Grants Program. The authors would like to thank Margaret Burchett, Angela Dacunto, Gemma Armstrong and Gabe O'Reilly for their assistance. 


\section{References}

Alexopoulos, C. J., Mims, C. W., \& Blackwell, M. (1996). Introductory Mycology. New York: John Wiley \& Sons.

Andersson, M., Downs, S., Mitakakis, T., Leuppi, J., \& Marks, G. (2003). Natural exposure to Alternaria spores induces allergic rhinitis symptoms in sensitized children. Pediatric Allergy and Immunology, 14(2), 100-105.

Atkinson, R. W., Strachan, D. P., Anderson, H. R., Hajat, S., \& Emberlin, J. (2006). Temporal associations between daily counts of fungal spores and asthma exacerbations. Journal of Occupational and Environmental Medicine, 63, 580-590.

Australian Bureau of Meteorology (2013-2014). http://www.bom.gov.au/nsw/forecasts/sydney.shtml Accessed 5 September 2013 - August 2014).

Australian Institute of Health and Welfare (AIHW)(2013). Asthma hospitalisations in Australia 2010-11. Cat. no. ACM 27). Canberra: AIHW.

Basilico, M., Chiericatti, C., Aringoli, E. E., Althaus, R. L., \& Basilico, J. C. (2007). Influence of environmental factors on airborne fungi in houses of Santa Fe City, Argentina. Science of The Total Environment, 376(1-3), 143-150.

Bass, D., Morgan, G. (1997). A three year (1993-1995) calendar of pollen and Alternaria mould in the atmosphere of south western Sydney. Grana, 36(5), 293-300.

Bauer, H., Schueller, E., Weinke, G., Berger, A., Hitzenberger, R., Marr, I. L., \& Puxbaum, H. (2008). Significant contributions of fungal spores to the organic carbon and to the aerosol mass balance of the urban atmospheric aerosol. Atmospheric Environment, 42(22), 5542-5549.

Bunse, T., \& Merk, H. (1992). Mycological aspects of inhalative mould allergies. Mycoses, 35(3-4), 61-66.

Burton, P. K., \& Katelaris, C. H. (2014). Aerobiological survey of fungal spores in Sydney: seasonal distribution of Didymella and Coprinus spores. In 10th International Congress of Aerobiology). Campbelltown, Australia.

Burch, M., \& Levetin, E. (2002). Effects of meteorological conditions on spore plumes. International Journal of Biometeorology, 46(3), 107-117.

Bush, R. (2009). Fungal Allergy as Yet Unsolved. In R. Pawankar, S. Holgate \& L. Rosenwasser (Eds.), Allergy Frontiers: Clinical Manifestations, vol. 3 (pp. 471-485): Springer Japan.

Crook, B., \& Burton, N. C. (2010). Indoor moulds, Sick Building Syndrome and building related illness. Fungal Biology Reviews, 24(3-4), 106-113.

Commonwealth Scientific and Industrial Research Organisation (CSIRO) (2010). Indoor air project Part 1: Main Report Indoor Air in Typical Australian Dwellings. A report to the Air Quality Section, Environment Standards Branch, Department of the Environment, Water, Heritage and the Arts. Commonwealth of Australia.

Comtois P., Morand S., Infante-Rivard C., Gautrin D., Vanderplass O. \& Malo J.-L. (1995) Exposure to spores during mowing: a comparative assessment of workers, parks and town. Aerobiologia 11, 145-50.

Dales, R. E., Cakmak, S., Judek, S., Dann, T., Coates, F., Brook, J. R., \& Burnett, R. T. (2004). Influence of outdoor aeroallergens on hospitalization for asthma in Canada. Journal of Allergy and Clinical Immunology, 113(2), 303-306.

Daft Logic Google Maps Distance Calculator (2013) http://www.daftlogic.com/projects-google-maps-distancecalculator.htm Accessed 12 October 2013

Denning, D. W., O'Driscoll, B. R., Hogaboam, C. M., Bowyer, P., \& Niven, R. M. (2006). The link between fungi and severe asthma: a summary of the evidence. European Respiratory Journal, 27(3), 615-626.

Derrick, E., McLennan, E.I. (1963). Fungus spores found in the air in Melbourne (Victoria), Australia. Acta Allergologica, XVIII, 26-43.

Dharmage, Bailey, Raven, Mitakakis, Thien, Forbes, Guest, Abramson, \& Walters. (1999). Prevalence and residential determinants of fungi within homes in Melbourne, Australia. Clinical \& Experimental Allergy, 29(11), 1481-1489.

Ellis, D. H., Davis, S., Alexiou, H., Handke, R., \& Bartley, R. (2007). Descriptions of Medical Fungi (2nd ed.). Adelaide, Australia: Women's and Children's Hospital. 
Fonseca, Á., \& Inácio, J. (2006). Phylloplane Yeasts. In G. Péter \& C. Rosa (Eds.), Biodiversity and Ecophysiology of Yeasts, (pp. 263-301): Springer Berlin Heidelberg.

Fröhlich-Nowoisky, J., Burrows, S. M., Xie, Z., Engling, G., Solomon, P. A., Fraser, M. P., Mayol-Bracero, O. L., Artaxo, P., Begerow, D., Conrad, R., Andreae, M. O., Després, V. R., Pöschl, U. (2012) Biogeography in the air: fungal diversity over land and oceans. Biogeosciences, 9,1125-1136

Frey, D., \& Durie, E. B. (1960). The incidence of airbourne fungus in Sydney. Mycopathologia, 13(2), 93-99.

Garrett, M., Hooper, B., Cole, F., \& Hooper, M. (1997). Airborne fungal spores in 80 homes in the Latrobe Valley, Australia: levels, seasonality and indoor-outdoor relationship. Aerobiologia, 13(2), 121-126.

Gaskin, S., Taylor, M., Bentham, R., \& Pisaniello, D. (2012). Understanding and managing risks associated with fungal contamination in indoor environments Final Report. In). Adelaide: The University of Adelaide.

Gots, R. E., Layton, N. J., \& Pirages, S. W. (2003). Indoor Health: Background Levels of Fungi. AIHA Journal, 64(4), 427-438.

Green, B. J., O'Meara, T., Sercombe, J. K., \& Tovey, E. R. (2006). Measurement of personal exposure to outdoor aeromycota in northern New South Wales Australia. Annals of Agricultural and Environmental Medicine, 13, 225-234.

Grinn-Gofroń, A., \& Bosiacka, B. (2015). Effects of meteorological factors on the composition of selected fungal spores in the air. Aerobiologia, 31(1), 63-72.

Grinn-Gofroń A, Rapiejko P (2009) Occurrence of Cladosporium spp.and Alternaria spp. spores in Western, Northern and Central-Eastern Poland in 2004 - 2006 and relation to some meteorological factors. Atmospheric Research 93:747-758

Green, C., Scarpino, P., \& Gibbs, S. (2003). Assessment and modeling of indoor fungal and bacterial bioaerosol concentrations. Aerobiologia, 19(3-4), 159-169.

Hanigan, I. C., \& Johnston, F. H. (2007). Respiratory hospital admissions were associated with ambient airborne pollen in Darwin, Australia, 2004-2005. Clinical \& Experimental Allergy, 37(10), 1556-1565.

Hargreaves, M., Parappukkaran, S., Morawska, L., Hitchins, J., He, C., \& Gilbert, D. (2003). A pilot investigation into associations between indoor airborne fungal and non-biological particle concentrations in residential houses in Brisbane, Australia. Science of The Total Environment, 312(13), 89-101.

Hasnain, S.M. (1993) Influence of meteorological factors on the air spora. Grana 32:184-188

Kauserud, H., Lie, M., Stensrud, Ø., \& Ohlson, M. (2005). Molecular characterization of airborne fungal spores in boreal forests of contrasting human disturbance. Mycologia, 97(6), 1215-1224.

Kemp, P. C., Neumeister-Kemp, H. G., Esposito, B., Lysek, G., \& Murray, F. (2003). Changes in Airborne Fungi from the Outdoors to Indoor Air; Large HVAC Systems in Nonproblem Buildings in Two Different Climates. AIHA Journal, 64(2), 269-275.

Klich, M. A., \& Pitt, J. I. (1988). A Laboratory Guide to Common Aspergillus Species and their Teleomorphs. Sydney Australia: CSIRO.

Kurkela, T. (1997). The number of Cladosporium conidia in the air in different weather conditions. Grana, 36(1), 54-61.

Lacey, J. (1981). The aerobiology of conidial fungi. In G. T. Cole \& W. B. Kendrick (Eds.), The Biology of Conidial Fungi, (pp. 373-416). New York: Academic Press.

Laflamme, A., \& Miller, J. D. (1992). Collection of spores of various fungi by a Reuter centrifugal sampler. International Biodeterioration \& Biodegradation, 29(2), 101-110.

Lang-Yona, N., Dannemiller, K., Yamamoto, N., Burshtein, N., Peccia, J., Yarden, O., Rudich, Y., \& MacKenzie, R. (2012). Annual distribution of allergenic fungal spores in atmospheric particulate matter in the Eastern Mediterranean; a comparative study between ergosterol and quantitative PCR analysis. Atmospheric Chemistry \& Physics, 12(5), 2681-2690.

Larone, D. H. (2002). Medically Important Fungi: A Guide to Identification, (4th ed.). Washington D.C: American Society for Microbiology Press.

Levetin, E., \& Horner, E. (2002). Fungal aerobiology: Exposure and measurement. Fungal Allergy and Pathogenicity, 81, 10-27. 
Lin, W.-H., \& Li, C.-S. (2000). Associations of Fungal Aerosols, Air Pollutants, and Meteorological Factors. Aerosol Science and Technology, 32(4), 359-368.

Mitakakis, T.Z., Clift, A., McGee, P.A. 2001. The effect of local cropping activities and weather on the airborne concentration of allergenic Alternaria spores in rural Australia. Grana, 40 (4-5), 230-239.

Mitakakis, T., \& Guest, D. (2001). A fungal spore calendar for the atmosphere of Melbourne, Australia, for the year 1993. Aerobiologia, 17(2), 171-176.

Mitakakis, T.Z., McGee, P.A. (2000). Reliability of measures of spores of Alternaria and pollen concentrations in air over two towns in rural Australia. Grana, 39, 141-145

Mitakakis, T.Z., Ong, E.K., Stevens, A., Guest, D., Knox, R.B. (1997). Incidence of Cladosporium, Alternaria and total fungal spores in the atmosphere of Melbourne (Australia) over three years. Aerobiologia, 13, 83-90.

Mitakakis, T. Z., Tovey, E. R., Xuan, W., \& Marks, G. B. (2000). Personal exposure to allergenic pollen and mould spores in inland New South Wales, Australia. Clinical \& Experimental Allergy, 30(12), 17331739.

Nishihara, T., Miyaji, T., Nasu, M., Takubo, Y., \& Kondo, M. (1989). Fungal flora in rainwater. Biomedical and Environmental Sciences, 2(4), 376-384.

O’Gorman, C. M. (2011). Airborne Aspergillus fumigatus conidia: a risk factor for aspergillosis. Fungal Biology Reviews, 25(3), 151-157.

Oliveira, M., Ribeiro, H., Delgado, J. L., \& Abreu, I. (2009). The effects of meteorological factors on airborne fungal spore concentration in two areas differing in urbanisation level. International Journal of Biometeorology, 53(1), 61-73.

Pongracic, J. A., O'Connor, G. T., Muilenberg, M. L., Vaughn, B., Gold, D. R., Kattan, M., Morgan, W. J., Gruchalla, R. S., Smartt, E., \& Mitchell, H. E. (2010). Differential effects of outdoor versus indoor fungal spores on asthma morbidity in inner-city children. Journal of Allergy and Clinical Immunology, 125(3), 593-599.

Quintero, E., Rivera-Mariani, F., \& Bolaños-Rosero, B. (2010). Analysis of environmental factors and their effects on fungal spores in the atmosphere of a tropical urban area (San Juan, Puerto Rico). Aerobiologia, 26(2), 113-124.

Recer, G., Browne, M., Horn, E., Hill, K., \& Boehler, W. (2001). Ambient air levels of Aspergillus fumigatus and thermophilic actinomycetes in a residential neighborhood near a yard-waste composting facility. Aerobiologia, 17(2), 99-108.

Ruiz-Camps, I., Aguado, J. M., Almirante, B., Bouza, E., Ferrer-Barbera, C. F., Len, O., Lopez-Cerero, L., Rodríguez-Tudela, J. L., Ruiz, M., Solé, A., Vallejo, C., Vazquez, L., Zaragoza, R., Cuenca-Estrella, M., \& Gemicomed. (2011). Guidelines for the prevention of invasive mould diseases caused by filamentous fungi by the Spanish Society of Infectious Diseases and Clinical Microbiology (SEIMC). Clinical Microbiology and Infection, 17, Supplement 2(0), 1-24.

Rutherford, S., Owen, J. A. K., \& Simpson, R. W. (1997). Survey of airspora in Brisbane, Queensland, Australia. Grana, 36(2), 114-121.

Sabariego, S., Díaz de la Guardia, C., \& Alba, F. (2000). The effect of meteorological factors on the daily variation of airborne fungal spores in Granada (southern Spain). International Journal of Biometeorology, 44, 1-5.

Sadyś, M., Strzelczak, A., Grinn-Gofroń, A., \& Kennedy, R. (2015). Application of redundancy analysis for aerobiological data. International Journal of Biometeorology, 59(1), 25-36.

Sharpe, R. A., Bearman, N., Thornton, C. R., Husk, K., \& Osborne, N. J. (2015). Indoor fungal diversity and asthma: A meta-analysis and systematic review of risk factors. Journal of Allergy and Clinical Immunology, 135(1), 110-122.

Simeray, J., Chaumont, J.-P., \& Léger, D. (1993). Seasonal variations in the airborne fungal spore population of the east of France (Franche - Comté). Comparison between urban and rural environment during two years. Aerobiologia, 9(2-3), 201-206.

Sousa, S. I. V., Martins, F. G., Pereira, M. C., Alvim-Ferraz, M. C. M., Ribeiro, H., Oliveira, M., \& Abreu, I. (2008). Influence of atmospheric ozone, PM10 and meteorological factors on the concentration of airborne pollen and fungal spores. Atmospheric Environment, 42(32), 7452-7464. 
Stennett, P.J., Beggs, P.J. 2004. Alternaria spores in the atmosphere of Sydney, Australia, and relationships with meteorological factors. International Journal of Biometeorology, 49, 98-105.

Streifel, A. J. (1988). Aspergillosis and Construction. In R. B. Kundsin (Ed.), Architectural Design and Indoor Microbial Pollution, (pp. 198-217). New York: Oxford University Press.

Tham, R., Dharmage, S. C., Taylor, P. E., Katelaris, C. H., Vicendese, D., Abramson, M. J., \& Erbas, B. (2014). Outdoor fungi and child asthma health service attendances. Pediatric Allergy and Immunology, 25(5), 429-449.

Thormann, M., Currah, R., \& Bayley, S. (2003). Succession of microfungal assemblages in decomposing peatland plants. Plant and Soil, 250(2), 323-333.

Torpy, F., Irga, P., Brennan, J., \& Burchett, M. (2013). Do indoor plants contribute to the aeromycota in city buildings? Aerobiologia, 29(3), 321-331.

Trimmer, L.W., Solel, Z., Gottwald, T.R., Ibanez, A.M., Zitko, S.E. (1998) Environmental factors affecting production, release, and field populations of conidia of Alternaria alternata, the cause of brown spot of citrus. Phytopathology 1998; 88: 1219-1223.

Vázquez de Aldana, B., Bills, G., \& Zabalgogeazcoa, I. (2013). Are endophytes an important link between airborne spores and allergen exposure? Fungal Diversity, 60(1), 33-42. 